\title{
Trends and characteristics affecting disability among older Canadians living in private households
}

\author{
Guillaume Lefrançois ${ }^{1}$ \\ Samuel Vézina \\ Janice Keefe \\ Jacques Légaré
}

\begin{abstract}
As the first of the Boomers reach age 65 in 2011, it is of great interest to identify trends in disability to better predict future needs and resources within community care. This paper uses data from four national datasets to investigate trends in disability rates and examine socio-demographic characteristics associated with disability. Results show a decrease in the overall disability prevalence rate. However, no significant trend in levels of disability was identified for the period 1994/95-2000/01 when controlling for socio-demographic variables, suggesting stability in the probability of being disabled over time.
\end{abstract}

Keywords: Disability, functional limitations, elderly, Canada.

\section{Résumé}

Avec l'arrivée des premiers boomers à l'âge de 65 ans, et pour mieux prévoir les besoins futurs de services à domicile, il est pertinent d'identifier les tendances en matière d'incapacité. Cet article utilise les données de quatre enquêtes nationales afin d'examiner l'évolution des taux d'incapacité et les caractéristiques sociodémographiques associées à l'incapacité. Les résultats montrent une diminution des taux d'incapacité globale. Toutefois, aucune tendance significative n'a été identifiée pour la période 1994/95-2000/01, après avoir contrôlé pour l'impact des variables sociodémographiques, ce qui suggère une stabilité de la probabilité d'être en état d'incapacité au cours de la période.

Mots-clés : handicap, limitations fonctionnelles, personnes âgées, Canada.

\section{Introduction}

Population aging is a consequence of outstanding and unprecedented progress made in the history of humanity; however, it is often perceived as a problematic process that is placing significant strain on pension and health systems, due to the increase in the proportion of older persons. Ill-

1 Guillaume Lefrançois, Department of Demography, Université de Montréal. Email: GLefrancois@cim-conseil. qc.ca. With Samuel Vézina, Maritime Data Centre for Aging Research and Policy Analysis, Mount Saint Vincent University (Halifax); Janice Keefe, Department of Family Studies and Gerontology, Mount Saint Vincent University (Halifax); and Jacques Légaré, Professor Emeritus, Department of Demography, Université de Montréal. 
Lefrançois et al.: Trends and characteristics affecting disability among older Canadians in private households

ness increases with age, and seniors are the greatest beneficiaries of healthcare and health services (Carrière 2006; Rotermann 2006). Moreover, according to the Canadian Institute for Health Information (CIHI), in 2009 healthcare spending by provincial and territorial governments was highest for infants and seniors. In that year, Canadians younger than age 1 cost an estimated $\$ 8,239$ per person, and from age 1 to age 64, spending averaged less than $\$ 3,809$ per person. However, per-capita spending increased dramatically in higher-age groups, increasing from $\$ 5,589$ for those aged $65-69$ to $\$ 17,469$ for those aged 80 and older (CIHI 2009).

Understanding disability trends can shed light on a population's need for supportive services. Analysis of international countries does not reveal clear evidence of compression, expansion, or equilibrium of morbidity. Lafortune et al. (2007) assessed recent evidence on trends in disability among the population aged 65 and over in 12 countries that are part of the Organization for Economic Cooperation and Development (OECD). This study reviewed trends in disability, with a special focus on severe disability — defined as one or more limitations in basic activities of daily living (ADLs), such as eating, bathing, and dressing_-given that such severe limitations tend to be closely related to demands for long-term care. One of the principal findings from this review is the divergence in trends among member countries, although results for Canada indicate a stable rate. Considerable heterogeneity in morbidity trends across developed countries has also been noted by Jagger et al. (2009).

In Canada, a few studies have assessed disability trends, and the results show no clear evidence of a trend in recent decades. Wilkins et al. (1994) estimated the trends in disability between two census dates (1986 and 1991). They found an increase in disability rates for the three age groups (65-74, 75-84, and 85+) for men and women, except for the male group aged 65-74 years old. This overall increase in disability seems to be the result of increased mild disability, as they found that rates of severe and moderate disability declined for men aged 65-74, and for women aged 65-85 years old.

However, Chen and Millar (2000) analysed the health status of recent Canadian cohorts compared with their predecessors, and reached a different conclusion. They compared the prevalence of some chronic diseases and disabilities of people aged 32-49, 50-67 and 68-85 years in 1996/97 to people of the same age in 1978/79. They concluded that for men and women in the three age groups, the prevalence of disability decreased between 1978/79 and 1996/97. However, when the effects of education and income are controlled for in the analyses, this trend disappears. In short, the improvement in health status observed in recent cohorts appears to be the result of higher levels of education and income, since the cohort and period effects disappear.

More recently, Statistics Canada published an analytical paper on the Participation and Activity Limitation Survey. It focused on the trend between the 2001 and 2006 survey, but no age-specific analyses were made to tackle particularities of the older population (Statistics Canada 2007). Finally, as mentioned above, Lafortune et al. (2007) reported that disability levels of older Canadians remained stable over the period 1996-2003 once the indicators are controlled for age effect and for some other social determinants of health, like income and education.

This article has two objectives. The first is to determine if the levels of disability significantly changed among older Canadians with a long-term health problem during the period 1994/95 to $2000 / 01$. The second objective is to determine the socio-demographic characteristics associated with older Canadians' levels of disability. As the boomers age, it is of great interest to identify trends in levels of disability and use of support networks among older Canadians with a long-term health problem, in order to better project future needs and resources, as it appears that disability is the strongest predictor of doctor and hospital utilisation among older people. Furthermore, regardless of age, disability is a strong predictor of home care use (McColl et al. 2011). 


\section{Data and methods}

\section{Data sources}

This research includes the secondary data analysis of four national datasets. First, data from the National Population Health Survey (NPHS for 1994/95, 1996/97, and 1998/99) and the Canadian Community Health Survey (CCHS for $2000 / 01^{2}$ ) were used to estimate changes in disability of older Canadians at the four points in time. Both the NPHS and CCHS have the same contextual framework, since the NPHS's cross-sectional content was transferred into the first cycle of the CCHS in 2000/01. Both surveys pursue the same objectives of collecting information on the general health of the Canadian population, health factors, and utilisation of health services. Target populations are also the same (i.e., households in all 10 provinces $^{3}$ ). Finally, both the NPHS and the CCHS excluded from their sampling frame individuals living on Indian Reserves and on Crown Lands, as well as institutional residents, full-time members of the Canadian Forces, and residents of some remote areas.

On the other hand, some key elements of the survey methodology varied from one cycle to another. Table 1 presents the distribution of the survey respondents according to the interview mode.

Table 1. Sample size and weighted distribution (\%) according to the interview mode, 1994/95-2000/01, NPHS and CCHS.

\begin{tabular}{lccc}
\hline \multirow{2}{*}{ Survey } & \multicolumn{2}{c}{ Interview mode } & \multirow{2}{*}{ Sample size } \\
\cline { 2 - 3 } & Face-to-face & Telephone & \\
\hline 1994/95 NPHS & 83.5 & 16.5 & 3,108 \\
1996/97 NPHS & 6.2 & 93.8 & 12,806 \\
1998/99 NPHS & 15.0 & 85.0 & 2,827 \\
2000/01 CCHS & 63.1 & 36.9 & 23,294 \\
\hline
\end{tabular}

First, differences are observed among the respondents' answers depending on the interview mode; experts say that despite the improving overall quality of phone interviews over time, the pattern of responses is more likely to be different when the interview is made over the phone rather than face-to-face (Link and Fahimi 2008). Moreover, St-Pierre and Béland (2004) found that the CCHS respondents aged 65 years old and over have a higher non-response rate for phone interviews than the younger respondents. Nonetheless, they concluded that these differences had no significant impact on most health indicators, including those related to chronic health problems and activity limitations. Another study, done by Côté and his colleagues (2005), focused on the differences in the response patterns due to sampling base changes between the 2000/01 and the 2003 CCHS. The distribution of respondents by variables related to activity limitations was found to be different due to the sampling base, but those differences were small (maximum variance of 2 per cent) and mostly not significant.

2 Our team attempted to undertake analyses on two additional points in time (for a total of six) using the 2003 and the 2005 CCHS. However, due to some issues encountered along the way regarding comparability problems and weighting issues of the 85+ age group, it was found more prudent to remove the 2003 and 2005 data points. Preliminary descriptive analyses revealed a decrease in the proportion of $85+$ within the $65+$ population in $2003 / 2005$, as well as a decrease in the population of $65+$ in $2003 / 2005$ that does not fit with official demographic observations.

3 The population in the northern territories are included in both the NPHS and the CCHS samples, but are excluded from the analysis, to ensure consistency with the overall research project. 
Lefrançois et al.: Trends and characteristics affecting disability among older Canadians in private households

\begin{tabular}{|c|c|c|c|c|c|}
\hline & $\begin{array}{c}1994 / 95 \\
\text { NPHS }\end{array}$ & $\begin{array}{c}1996 / 97 \\
\text { NPHS }\end{array}$ & $\begin{array}{c}1998 / 99 \\
\text { NPHS }\end{array}$ & $\begin{array}{c}2000 / 01 \\
\text { CCHS }\end{array}$ & $\begin{array}{c}1994 / 95- \\
2000 / 01\end{array}$ \\
\hline \multicolumn{6}{|l|}{ Age groups } \\
\hline $65-74$ & 63.2 & 61.7 & 57.4 & 59.4 & 60.4 \\
\hline $75-84$ & 29.8 & 30.9 & 35.0 & 32.8 & 32.2 \\
\hline $85+$ & 7.1 & 7.4 & 7.6 & 7.9 & 7.5 \\
\hline \multicolumn{6}{|l|}{ Sex } \\
\hline Men & 43.0 & 43.2 & 43.5 & 43.7 & 43.4 \\
\hline Women & 57.0 & 56.8 & 56.5 & 56.3 & 56.6 \\
\hline \multicolumn{6}{|l|}{ Schooling level } \\
\hline Less than high school dipl. & 53.7 & 51.2 & 50.2 & 49.9 & 51.2 \\
\hline High school diploma & 12.5 & 15.7 & 13.8 & 16.1 & 14.6 \\
\hline Post-sec. dipl. other than univ. & 26.3 & 25.6 & 27.9 & 23.2 & 25.7 \\
\hline University degree & 7.6 & 7.6 & 8.0 & 10.8 & 8.5 \\
\hline \multicolumn{6}{|l|}{ Marital status } \\
\hline Married/in union & 59.3 & 58.9 & 57.4 & 60.5 & 59.0 \\
\hline Single & 5.1 & 5.5 & 4.5 & 4.8 & 5.0 \\
\hline Widowed/separated/divorced & 35.6 & 35.6 & 38.1 & 34.7 & 36.0 \\
\hline \multicolumn{6}{|l|}{ Region } \\
\hline Atlantic & 8.5 & 8.3 & 8.1 & 8.0 & 8.2 \\
\hline Quebec & 24.2 & 25.0 & 24.2 & 24.5 & 24.5 \\
\hline Ontario & 38.0 & 37.2 & 38.5 & 38.7 & 38.1 \\
\hline Prairies & 15.9 & 15.7 & 15.7 & 15.5 & 15.7 \\
\hline British Columbia & 13.4 & 13.8 & 13.4 & 13.4 & 13.5 \\
\hline \multicolumn{6}{|l|}{ Country of birth } \\
\hline Canada & 75.3 & 75.4 & 72.4 & 72.3 & 73.8 \\
\hline Outside Canada & 24.7 & 24.6 & 27.6 & 27.0 & 26.0 \\
\hline $\mathrm{N}$ & $3,201,000$ & $3,324,000$ & $3,461,000$ & $3,533,000$ & $13,518,000$ \\
\hline
\end{tabular}

Table 1 shows the size of each of the four samples and the relative distribution of these samples according to the interview mode. First, the sample size variation has implications for the resulting estimates, since the sample size is inversely proportional with the sampling errors and the estimates variance. The 2000/01 sample counts for about 55 per cent of the total sample, while those of 1994/95 and 1998/99 are about 7 per cent each. Therefore, the large size of the sample reported here (42,035 respondents) is mainly the result of the 2000/01 sample. Second, we observe important variations in the percentage of telephone interview (from 16.5 per cent in 1994/95, it rose to 94.8 per cent in 1996/97 and decreased to 36.9 per cent in 2000/01).

In light of these observations, it became obvious that these important comparability issues could not be ignored in the analyses of the data. Estimates obtained with the NPHS and the CCHS must be cautiously interpreted, knowing the existing methodological differences of the survey designs. A paper by Wolf et al. (2005) reviewed the ambiguities in measuring disability using large-scale household surveys, illustrating the consequences of such problems on the interpretation of results.

Table 2 presents the distribution of respondents by socio-demographic characteristics and year of interview. It reveals that the population aged 65 and older estimated from surveys is growing through the period, increasing from 3,201,000 in 1994/95 to 3,533,000 in 2000/01. Moreover, the group aged 85 and older is gaining importance within the older population. Also notable is that schooling level is improving, since fewer people have no diploma, and more people have a university degree. 


\section{Variable definitions}

In each of the four datasets (NPHS and CCHS), level of disability was measured using widely accepted standard variables, specifically designed for assessment of health-related quality of life (Feeny et al. 2002). These variables are called the Health Utility Index variables (HUI). They explore eight dimensions of an individual's health status. The HUI, based on the Comprehensive Health Status Measurements System (CHSMS), takes into account both the quantitative and qualitative aspects of health (Torrance et al. 1996). It provides information on the functional health of an individual using a series of attributes. For the purpose of this study, only those dimensions that are correlated with the need for long-term assistance were retained to develop four levels of disability, as advocated by Carrière et al. (2007). Therefore, out of the eight HUI modules, only the following five were retained. These included: 1) Mobility (ability to get around); 2) Dexterity (use of hands and fingers); 3) Cognition (memory and thinking); 4) Vision; and 5) Pain and discomfort.

Hearing, speech, and emotional dimensions did not meet the criteria and were excluded from the disability definition. For the purposes of this analysis, level of disability is treated as ranging from no disability to mild, moderate, or severe disability. Table 3 shows the classification system used to define an individual's disability level.

On the basis of one's scores in each of the five modules listed above, a disability level was attributed based on an individual's response. For example, respondents without any vision problems were considered to have "No disability," whereas a "Severe" disability level was attributed to respondents who declared having "No sight at all." Respondents' levels of functionality are assessed in each of the five health dimensions. The dimension with the highest level of disability defines one's disability level for the purpose of this analysis. For example, if an individual has no sight (considered to be a severe disability), but has no problem at all in any of the other four dimensions, the disability level attributed to this person is still "Severe disability." Therefore, this classification system does not take into account any additional lower level disabilities. It also means that a respondent with a moderate disability in only one dimension and no disability in other dimensions is classified in the same category as another respondent with a moderate disability in more than one dimension. This system has proven efficient over the years at categorizing the general disability levels of the population, and has been used by several Canadians researchers (e.g., Wolfson and Rowe 2005; Carrière et al. 2007; Wolfson and Moore 2010; Lefrançois 2011).

\section{Analytical approach}

A descriptive analysis of the data was undertaken in order to identify the observed prevalence of disability among older Canadians, as measured in the different datasets. An inferential analysis (regression analysis) was then undertaken to identify trends over time, taking into account the different changes that occur in the socio-demographic distribution of the older population between 1994 and 2001. Finally, a regression model was developed and parameters were calculated, thereby revealing the characteristics of older Canadians associated with disability.

To understand the evolution of overall disability and to determine if trends are significant over time, the four datasets were pooled into one single database, and a variable was created to identify the year of interview. A multinomial logit analysis with disability as the dependent variable, and "year" as one of the independent variables, was then performed to determine if the probability of being disabled changed over time. The significance of the net impact of the "year" variable on disability allowed the presence or absence of trends over the period to be assessed, taking into account the 
Lefrançois et al.: Trends and characteristics affecting disability among older Canadians in private households

Table 3. Multi-dimension disability level classification system using HUI variables.

\begin{tabular}{|c|c|c|c|c|c|}
\hline \multirow{2}{*}{$\begin{array}{c}\text { HUI } \\
\text { Dimension }\end{array}$} & \multirow[b]{2}{*}{ Level and description of the level of functionality } & \multicolumn{4}{|c|}{ Disability level } \\
\hline & & No & Mild & $\begin{array}{l}\text { Mod- } \\
\text { erate }\end{array}$ & $\begin{array}{l}\text { Sev- } \\
\text { ere }\end{array}$ \\
\hline Vision & $\begin{array}{l}1 \text { No visual problem } \\
2 \text { Problems corrected by lenses (distance, close, or both) } \\
3 \text { Problems seeing distances - not corrected } \\
4 \text { Problems seeing close - not corrected } \\
5 \text { Problems not corrected by lenses (distances, close, or both) } \\
6 \text { No sight at all }\end{array}$ & $\begin{array}{l}X \\
X \\
X\end{array}$ & $X$ & $\mathrm{X}$ & $\mathrm{X}$ \\
\hline Mobility & $\begin{array}{l}1 \text { No mobility problem } \\
2 \text { Problem - no aid required } \\
3 \text { Problem - requires mechanical support } \\
4 \text { Problem - requires wheelchair } \\
5 \text { Problem - requires help from people } \\
6 \text { Cannot walk }\end{array}$ & $\mathrm{X}$ & $\mathrm{X}$ & $\begin{array}{l}X \\
X\end{array}$ & $\begin{array}{l}X \\
X\end{array}$ \\
\hline Dexterity & $\begin{array}{l}1 \text { No dexterity problem } \\
2 \text { Dexterity problems - no help nor equipment required } \\
3 \text { Dexterity problems - requires special equipment } \\
4 \text { Dexterity problems - requires help for some tasks } \\
5 \text { Dexterity problems - requires help for most tasks } \\
6 \text { Dexterity problems - requires help for all tasks }\end{array}$ & $\mathrm{X}$ & $\begin{array}{l}X \\
X\end{array}$ & $\mathrm{X}$ & $\begin{array}{l}X \\
X\end{array}$ \\
\hline $\begin{array}{l}\text { Memory and } \\
\text { Thinking }\end{array}$ & $\begin{array}{l}1 \text { No cognitive problem } \\
2 \text { Having a little difficulty to think } \\
3 \text { Somewhat forgetful } \\
4 \text { Somewhat forgetful/Having a little difficulty to think } \\
5 \text { Very forgetful/Some difficulty to think } \\
6 \text { Unable to think and to remember }\end{array}$ & $\begin{array}{l}X \\
X \\
X\end{array}$ & $\mathrm{X}$ & $\mathrm{X}$ & $X$ \\
\hline $\begin{array}{l}\text { Pain and } \\
\text { discomfort }\end{array}$ & $\begin{array}{l}1 \text { No pain or discomfort } \\
2 \text { Mild or moderate pain; does not prevent activity } \\
3 \text { Moderate pain; prevents few activities } \\
4 \text { Moderate or severe pain; prevents some activities } \\
5 \text { Moderate or severe pain; prevents most activities }\end{array}$ & $\begin{array}{l}X \\
X\end{array}$ & $\begin{array}{l}X \\
X\end{array}$ & X & \\
\hline
\end{tabular}

impact of the other socio-demographic factors that are identified in the literature as being associated with disability. Those independent variables are as follows: age (10-year groups from 65 to $85+$ ), sex, marital status (married/in-union, single and widowed/separated/divorced), schooling level (less than high school diploma, high school diploma, post-secondary diploma other than university, and university degree), region (Atlantic Canada, Quebec, Ontario, the Prairies, and British Columbia), and country of birth (Canada or outside of Canada). Two variables are also included to control for the impacts of changes in the survey methodology (as discussed above): the data collection mode (by phone or in person) and the interview mode (i.e., whether the interview was completed by a proxy). Finally, given the fact that the complex sampling frames of the datasets increase the uncertainty (variance) of the estimated parameters, bootstrap weights provided by Statistics Canada were used to weight the results. 
Finally, the assessment of characteristics associated with older Canadians' levels of disability is done by a second multivariate logit model, which incorporates the same dependent and independent variables as the first model. This analysis was performed on the 2000/01 CCHS, which is the most recent and largest dataset.

Table 4. Overall disability rate and distribution of disabled Canadians aged 65 and older living in private households by severity levels and socio-demographic characteristics, 1994/95 to 2000/01.

\begin{tabular}{|c|c|c|c|c|c|}
\hline Independent variables & $\begin{array}{c}\text { Mild } \\
\text { disability }\end{array}$ & $\begin{array}{l}\text { Moderate } \\
\text { disability }\end{array}$ & $\begin{array}{c}\text { Severe } \\
\text { disability }\end{array}$ & $\begin{array}{c}\text { Total } \\
\text { disability }\end{array}$ & $\begin{array}{c}\text { Overall } \\
\text { disability rate } \\
\end{array}$ \\
\hline Total & 49.4 & 36.0 & 14.5 & 100 & 34.4 \\
\hline \multicolumn{6}{|l|}{ Age groups } \\
\hline $65-74$ & 61.1 & 30.0 & 8.8 & 100 & 27.5 \\
\hline $75-84$ & 43.4 & 39.2 & 17.3 & 100 & 40.8 \\
\hline $85+$ & 24.7 & 48.8 & 26.4 & 100 & 62.8 \\
\hline \multicolumn{6}{|l|}{ Sex } \\
\hline Men & 48.7 & 38.9 & 12.3 & 100 & 30.4 \\
\hline Women & 49.8 & 34.3 & 15.8 & 100 & 37.5 \\
\hline \multicolumn{6}{|l|}{ Schooling level } \\
\hline Less than high school dipl. & 48.9 & 34.8 & 16.3 & 100 & 38.2 \\
\hline High school diploma & 48.0 & 37.1 & 14.9 & 100 & 30.6 \\
\hline Post-sec. dipl. other than univ. & 52.3 & 37.2 & 10.5 & 100 & 31.6 \\
\hline University degree & 47.7 & 39.9 & 12.4 & 100 & 26.0 \\
\hline \multicolumn{6}{|l|}{ Marital status } \\
\hline Married/in union & 53.5 & 33.4 & 13.1 & 100 & 31.8 \\
\hline Single & 43.7 & 42.2 & 14.1 & 100 & 32.8 \\
\hline Widowed/separated/divorced & 44.6 & 38.9 & 16.5 & 100 & 39.1 \\
\hline \multicolumn{6}{|l|}{ Region } \\
\hline Atlantic & 48.0 & 36.1 & 15.9 & 100 & 31.4 \\
\hline Quebec & 53.6 & 30.4 & 16.0 & 100 & 31.9 \\
\hline Ontario & 47.8 & 37.7 & 14.5 & 100 & 35.3 \\
\hline Prairies & 47.2 & 39.9 & 12.8 & 100 & 36.9 \\
\hline British Columbia & 49.7 & 37.2 & 13.2 & 100 & 35.5 \\
\hline \multicolumn{6}{|l|}{ Country of birth } \\
\hline Canada & 48.7 & 36.7 & 14.6 & 100 & 33.2 \\
\hline Outside Canada & 50.8 & 34.7 & 14.5 & 100 & 37.8 \\
\hline
\end{tabular}

\section{Results}

\section{Disability rates between 1994/95 and 2000/01: Descriptive results}

As can be seen from Table 4, the overall disability rate in Canada between 1994/95 and 2000/01 was 34.4 per cent, with survey data revealing that nearly one in three persons aged 65 years and over was disabled at some level (i.e., regardless of severity). Among these persons with a disability, 49.4 per cent presented with a mild disability, 36.0 per cent with a moderate disability, and 14.5 per cent with a severe disability (Table 4). With close to half of the total disabled population having a mild disability, a substantial number of disabled persons may need home care services. People with a moderate or severe disability may be in a situation where home care is needed if they are to remain in their own homes. These individuals accounted for 50.6 per cent of the disabled older population, which represents 17.4 per cent of the total Canadian population aged 65 and older during the given time period. 
Lefrançois et al.: Trends and characteristics affecting disability among older Canadians in private households

Table 4 also presents the distribution of people aged 65 and older by socio-demographic characteristics. The proportion of disabled individuals is higher in older-age groups, higher among women, and higher among individuals born outside of Canada. On the other hand, the proportion of disabled persons is lower among married people, and it decreases as schooling level increases. In addition, the overall disability rate varies across the country, from 31.4 per cent in the Atlantic region to 36.9 per cent in the Prairies.

Levels of severity are similarly affected by socio-demographic characteristics (Table 4). For example, we observed increases in severity levels with age and decreases in severity levels as the schooling level rises. In relative terms, men show higher proportions of moderate disability than women, but, as previously noted, the opposite situation prevails for severe disability. Moderate disabilities are less common among married/in-union people, and for individuals living in Quebec. Finally, severe disability is higher among the widowed, separated, or divorced and in the Atlantic provinces. These results generally fit with other descriptive analyses within the existing literature. The highest rate of severe disability is nonetheless found in the Prairies, while one would have expected to see this in the Atlantic Region (Statistics Canada 2007). However, our results indicate that severity levels of disabled individuals in the Atlantic provinces are higher than those of disabled older persons in the Prairies.

Table 5. Overall disability rate and distribution of severity levels (\%) by year, 1994/95-2000/01, Canadians aged 65 and over living in private households.

\begin{tabular}{lccccc}
\hline Disability levels & $1994 / 95$ & $1996 / 97$ & $1998 / 99$ & $2000 / 01$ & $\begin{array}{c}1994 / 95- \\
2000 / 01\end{array}$ \\
\hline Overall disability & 37.7 & 31.4 & 34.8 & 33.9 & 34.4 \\
Mild disability & 53.2 & 48.5 & 49.1 & 46.9 & 49.4 \\
Moderate disability & 34.1 & 35.9 & 36.3 & 37.9 & 36.0 \\
Severe disability & 12.7 & 15.6 & 14.6 & 15.2 & 14.5 \\
\hline N & $3,201,000$ & $3,324,000$ & $3,461,000$ & $3,533,000$ & $13,518,000$ \\
\hline
\end{tabular}

Note: The distribution of disability levels is calculated among the disabled population.

The rates presented in Table 4 are weighted averages over the years, and indicate the average level of disability observed between 1994/95 and 2000/01. These reflect adequately the reality over the period, assuming that no trend, either upward or downward, occurred during that time (i.e., that morbidity within the population did not decline or expand). Table 5 presents the overall disability rates for each of four survey years, and the distribution across severity levels. The rates are not constant over time, and are not consistently increasing or decreasing either, with the exception of moderate disability, which has increased steadily between 1994/95 and 2000/01.

As can be seen in Table 5, the proportion of disabled people, regardless of severity levels, was very high in 1994/95 as compared to other years, but especially compared to 1996/97. The important difference in the distribution of respondents according to the year of interview and the mode of interview may be an explanation. In relative terms, the overall disability rate was approximately 20 per cent higher in 1994/95 than in 1996/97, and 10 per cent higher than the average for the period $1994 / 95$ to $2000 / 01$. As it constitutes almost half of the overall disability, mild disability was also exceptionally high in 1994/95 - about 10 per cent higher than in 1996/97 and 8 per cent higher compared to the average for the period 1994/95 to 2000/01.

These numbers are illustrated in Figures 1 and 2, on which were added trend lines estimated by the ordinary least-squares method. This method allows one to see the graphic representation of the general trend of overall disability over time, even if the trend lines are influenced by outliers (as our 
lines are estimated from four points in time, outliers may have an important impact). Furthermore, not controlling for changing socio-demographic variables constitutes a descriptive illustration of the situation.

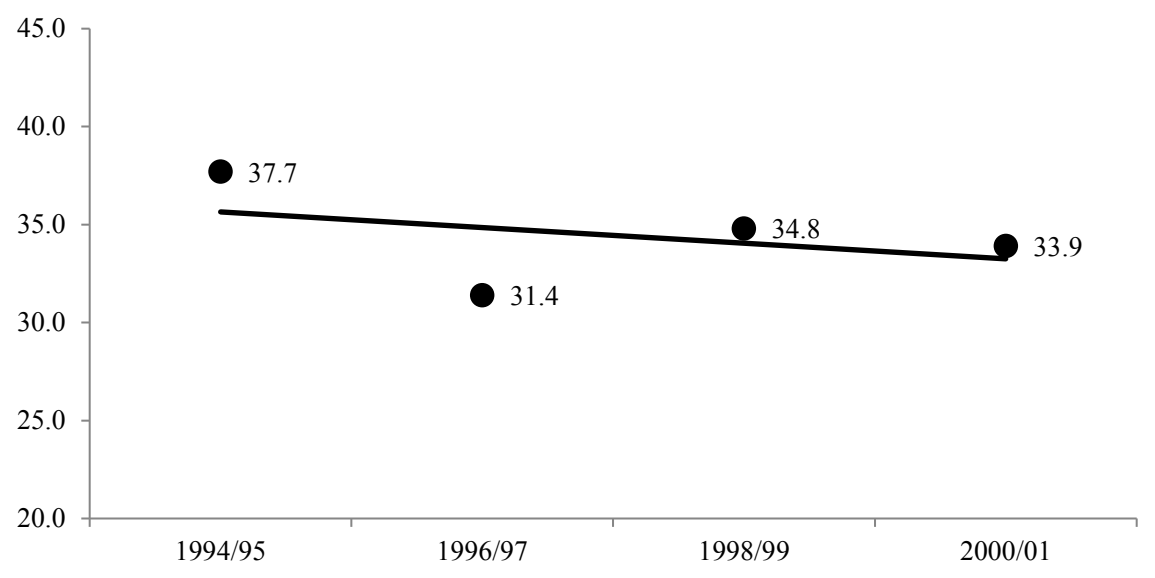

Figure 1. Overall disability rate (\%) according to years for Canadians aged 65 and older living in private households, 1994/95 to 2000/01.

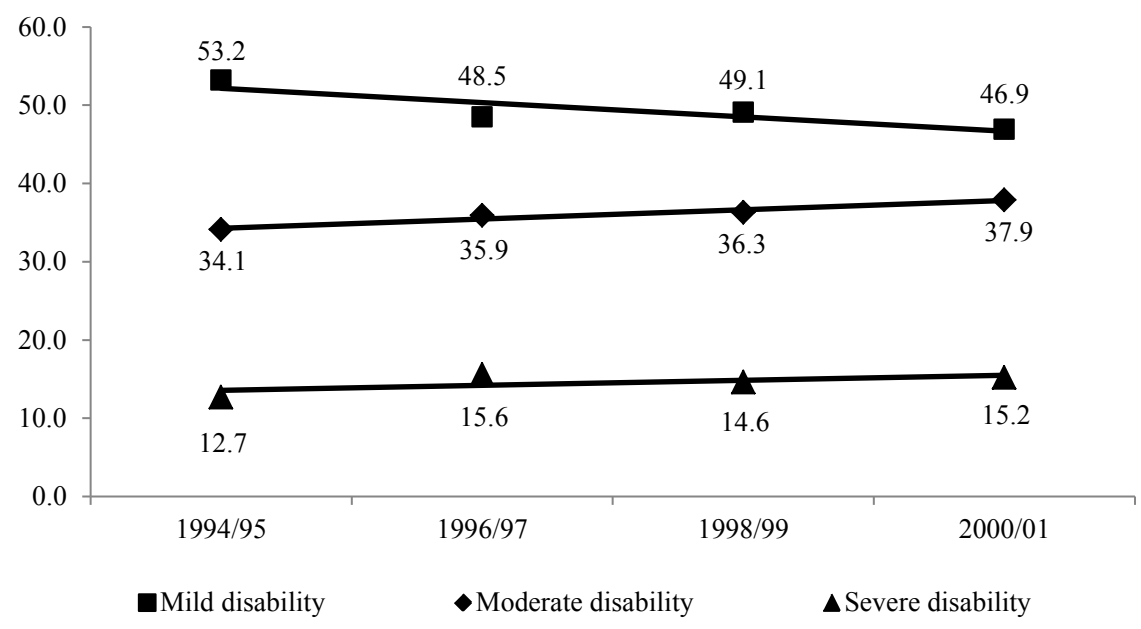

Figure 2. Distribution of disabled Canadians aged 65 and older living in private households by severity levels, 1994/95 to 2000/01. Note: The distribution of disability levels is calculated among the disabled population.

Figure 1 shows the evolution of the overall disability rate. As mentioned above, the first two points are relatively far from the trend line, as well as from the points observed for the years 1998/99 and 2000/01. Nonetheless, a downward trend is observed, as the overall disability rates decrease from 37.7 per cent in 1994/95 to 33.9 per cent in 2000/01. This decrease is about 1.4 per cent annually. Figure 2 shows the evolution of the disability rates by severity (this is the proportion of each severity level among the total number of disabled older persons). First, there was a decrease in the proportion of mild disabilities, which was especially prominent at the beginning of the period. The proportion of moderate disabilities increased throughout the period. The decrease in mild disabilities and the increase of moderate disabilities are reflective of one another. The proportion of severely 
disabled older persons remains quite stable between 1996/97 and 2000/01. Even if there is no real upward trend in severe disability, the rate increased from 12.7 per cent in 1994/95 to 15.5 per cent in $2000 / 01$.

Two conclusions emerge from these results. First, given the declining rate of overall disability over the period, improvement appears to have occurred in the overall functional health of older persons. However, the severity of the disability seems to have worsened, due to the decrease in the proportion of individuals with mild disabilities and the increase of those with moderate disabilities. This decline in overall disability, along with the mild disability rates observed in Canada, are consistent with what is observed in the United States (Waidmann and Liu 2000; Schoeni et al. 2001; Freedman et al. 2004; Schoeni et al. 2008). Also, the relative stagnation of severe disability is consistent with results published by Lafortune et al. (2007) on older Canadians between 1996/97 and 2003.

However, the mode of interview changed significantly across the NPHS and CCHS cycles, which may constitute a limitation in the comparability of the estimates. Indeed, the highest overall disability rate was recorded by the survey with the highest rate of respondents interviewed face to face, and the lowest rate was recorded by the survey with the highest rate of respondents interviewed by phone. The impact of this methodology change is more difficult to assess in regard to severity; however, the highest severe disability rate is recorded in the same years that the overall disability rate is the lowest, and the opposite is true for the lowest severe disability rate.

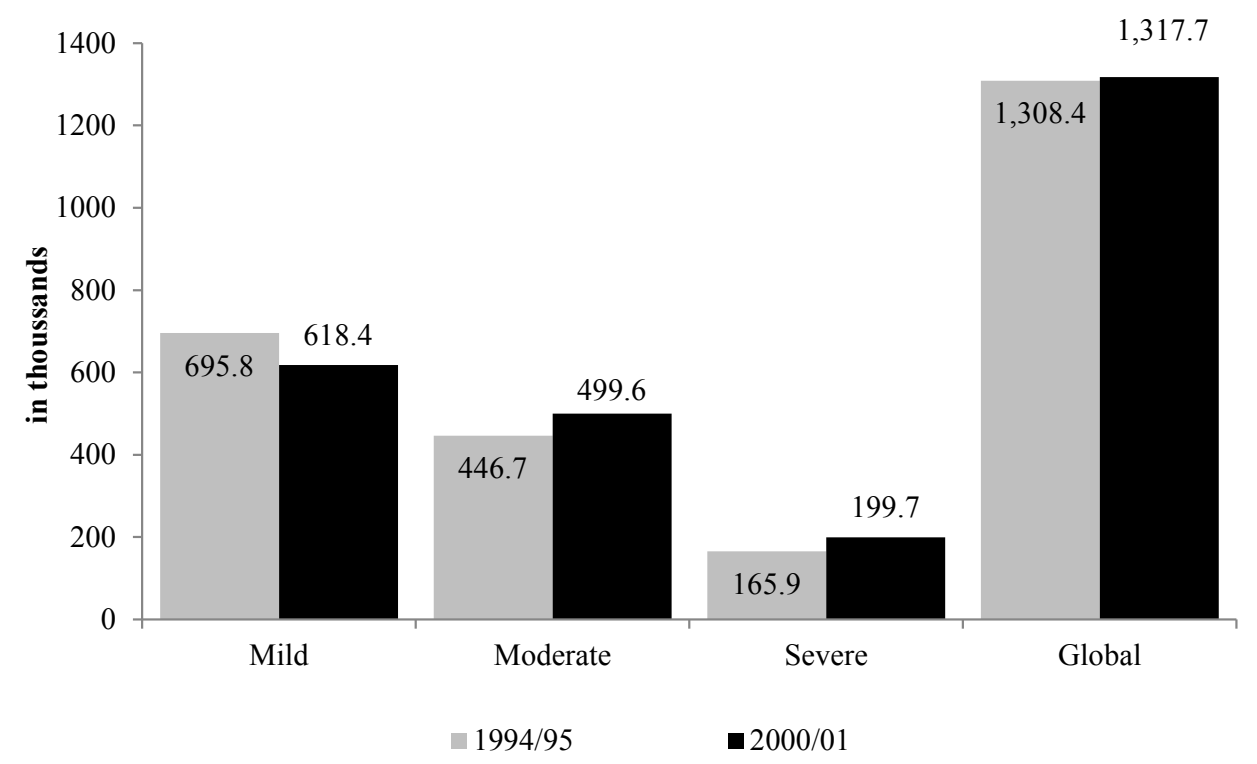

Figure 3. Variation, in crude numbers, of disabled Canadians aged 65 and older living in private households between 1994/95 and 2000/01.

The decrease observed in disability rates reduced the gross impact of population aging on the number of disabled older persons. According to the estimates by Statistics Canada (2010), the population aged 65 years and over increased by 12 per cent between 1994/95 and 2000/01. If there had been no downward trend in disability rates, the same increase in the number of older disabled persons would have been observed. However, by applying the rates of disability presented in Table 6 to the estimates of the population aged 65 and over, the number of disabled older persons has increased by only 1 per cent, from 1,308,400 in 1994/95 to 1,317,700 
in 2000/01 (Figure 3). If the number of disabled people had increased at the same rate as the population aged 65 and over, there would have been 1,465,400 disabled older persons in 2000/01. Figure 3 also shows that there has been a change in the distribution of disabled older persons by the levels of severity. There was an 11 per cent decline in the number of persons with a mild disability, while there was an increase of 12 per cent in moderate disability and an increase of 20 per cent in severe disability.

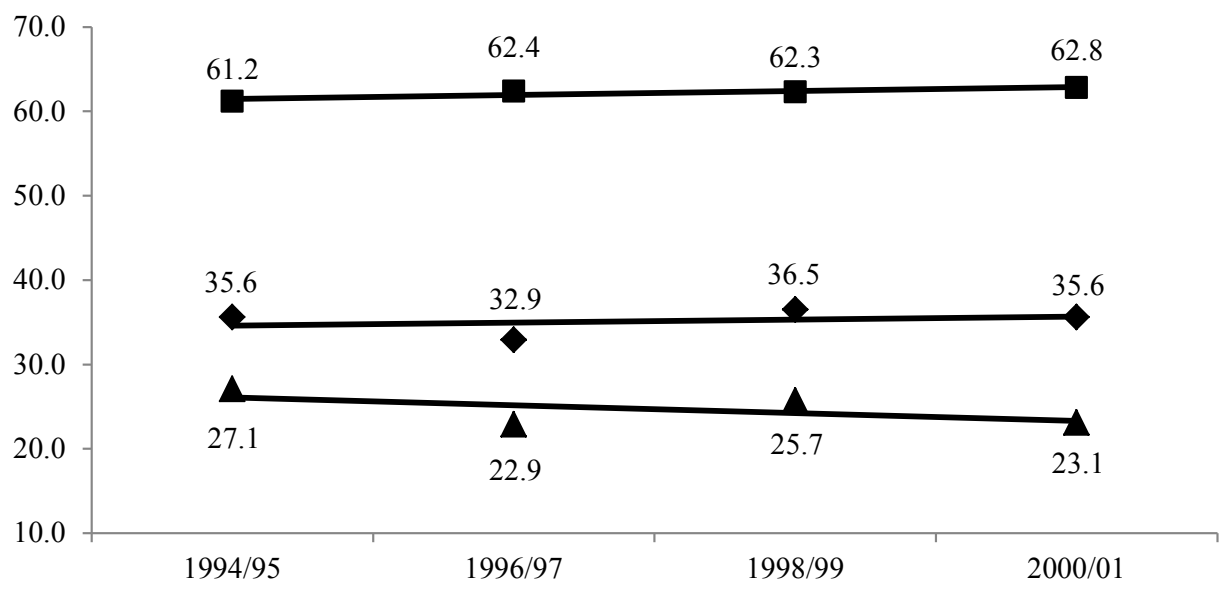

Disabled males aged 85+ $\diamond$ Disabled males aged 75-84 $\Delta$ Disabled males aged 65-74

Figure 4. Distribution of male disabled Canadians aged 65 and older living in private households by age groups, 1994/95 to 2000/01.

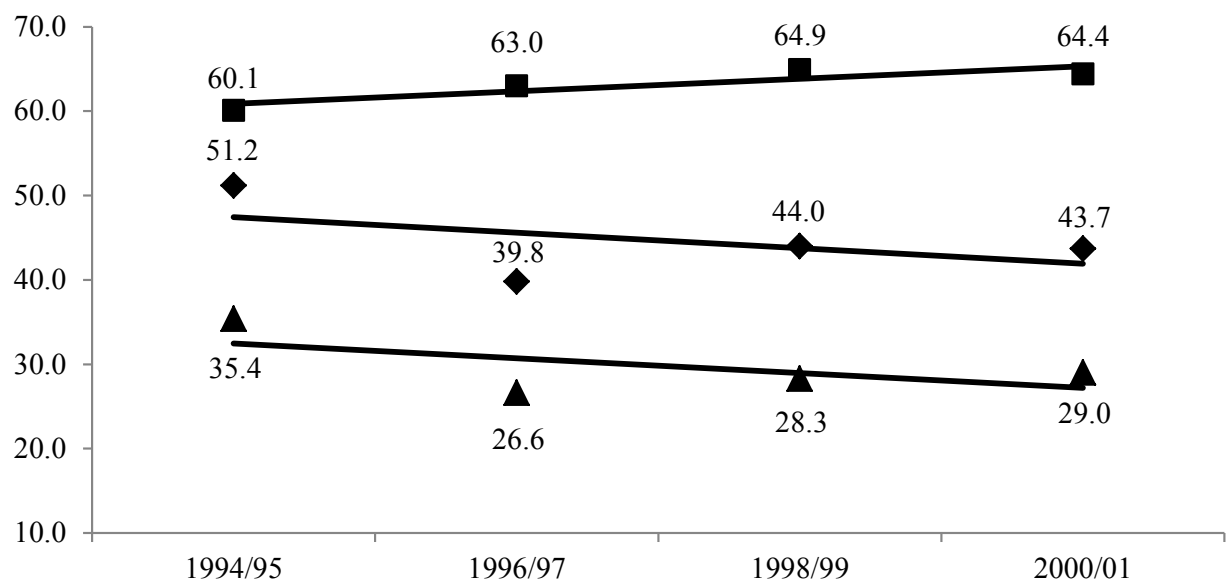

$\boldsymbol{D}$ Disabled females aged 85+ $\diamond$ Disabled females aged 75-84 $\Delta$ Disabled females aged 65-74

Figure 5. Distribution of female disabled Canadians aged 65 and older living in private households by age groups, 1994/95 to 2000/01.

As illustrated in Table 4, the disability prevalence varies, sometimes significantly, depending on the socio-demographic characteristics of the population, especially depending on its age structure. The analysis of the trends presented so far does not take into account the changes in the structure of 
the population between the years 1994/95 and 2000/01. It is therefore surprising to see the overall disability rate decreasing between 1994/95 and 2000/01, while the 65 years and over population is aging (the proportion of the 65-74 in the 65+ age group is decreasing over the period, but increasing in the 85+). Figures 4 and 5 present distributions by age and sex of disabled older Canadians by severity level. As the rate of overall disability dropped during the period, some declining and rising disability rates are observed, when broken down by age group and sex. The disability rates decreased among males and females 65-74 years old, and increased for males and females 85 and older. However, the increase for females $85+$ is more important than for males. For the 75-84-year-old group, the prevalence of disability remained fairly stable for males, but it decreased for females. These results show an improvement of functioning for younger males, and no trends for those $75+$. For females, the results show an improvement of functioning for those 75 years and under, and a decline for the 85+. However, looking at the trends between 1996/97 and 2000/01 (and ignoring the year 1994/95), there is no change for younger men, but an increase of 2.6 points for younger women, and an increase of 3.9 points for women aged 75-84 years.

This initial descriptive analysis establishes summary indicators in disability rates in Canada between 1994/95 and 2000/01. Because many variables can affect the functional health of older persons, it is somewhat risky at this stage to draw conclusions about the presence or absence of significant changes. However, according to these results, four points are apparent:

1. The overall disability rate among older Canadians living in private households was 34.4 per cent, and almost half of these disabled people had a mild condition.

2. A decrease in overall disability rates was observed; however, there was an increase in the severity of the condition of disabled people, as there was a decrease in mild disabilities and an increase in moderate and severe disabilities.

3. The decrease in overall disability is due mainly to improved health (as measured by HUI) among persons 65-74 years old (men and women), and among women aged 75-84 years old.

4. The decrease in the evolution of the overall disability rate mitigates the impact of aging on the number of disabled older persons, but is not strong enough to offset its effect.

The next section will examine the trends described above by testing the impact of the variable of interest, the survey year, in a multivariate regression model. This will allow the presence or absence of statistically significant trends, taking into account the effects of other socio-demographic factors, to be determined. 
Table 6. Regression parameters associated to the years on the risk of being disabled for Canadians aged 65 and older living in private households, 1994/95 to 2000/01.

\begin{tabular}{|c|c|c|c|}
\hline & Beta & Odds ratio & P-value \\
\hline \multicolumn{4}{|l|}{ No disability $^{(1)}$} \\
\hline \multicolumn{4}{|l|}{ Mild disability } \\
\hline $1994-95^{(2)}$ & - & - & - \\
\hline 1996-97 & -0.267 & 0.765 & 0.605 \\
\hline 1998-99 & -0.128 & 0.880 & 0.827 \\
\hline $2000-01$ & -0.262 & 0.770 & 0.512 \\
\hline \multicolumn{4}{|c|}{ Moderate disability } \\
\hline $1994-95^{(2)}$ & - & - & - \\
\hline 1996-97 & 0.035 & 1.036 & 0.950 \\
\hline 1998-99 & 0.127 & 1.135 & 0.834 \\
\hline $2000-01$ & -0.037 & 0.964 & 0.928 \\
\hline \multicolumn{4}{|c|}{ Severe disability } \\
\hline $1994-95^{(2)}$ & - & - & - \\
\hline 1996-97 & 0.179 & 1.196 & 0.841 \\
\hline 1998-99 & 0.198 & 1.219 & 0.842 \\
\hline $2000-01$ & -0.039 & 0.962 & 0.958 \\
\hline \multicolumn{4}{|l|}{$\mathrm{n}=42,035$} \\
\hline $\begin{array}{l}\text { 1. Dependent va } \\
\text { 2. Independent } \\
* * * p \leq 0.01 ; * *\end{array}$ & $\begin{array}{l}\text { rence ca } \\
\text { ference }\end{array}$ & $\begin{array}{l}\text { ry } \\
\text { gories } \\
<p \leq 0\end{array}$ & \\
\hline
\end{tabular}

\section{Trends in disability in Canada between 1994/95 and 2000/01: Multivariate results}

Table 6 presents the results of the multinomial logit model used to test the presence or absence of a significant trend in disability between 1994/95 and 2000/01. The model includes all independent variables (survey year, age, sex, education, marital status, region of residence, and country of origin) and control variables (respondents by proxy and mode of data collection, i.e., by phone or in person). The variable of interest is survey year; parameters associated with other variables in the model are not presented.

First, the odds ratios (OR) for each year, and for three levels of disability, are relatively close to 1 , indicating that none of the years present a significant change in the risk of being disabled (mild, moderate, or severe) compared to 1994/95, all being equal. However, the decline in mild disability described above still holds, even when controlling for the effect of changes in the socio-demographic structure of the population. Even if the OR estimates are not significant and do not show a linear trend, they are all less than 1 . This means that the risk of being mildly disabled is lower for each year between 1996/97 and 2000/01 than in 1994/95, but the sample variance is too high to have a statistically significant trend. Regarding the risk to have a moderate disability, the upward trend observed earlier disappears, since the risk (OR) in 2000/01 is less than in the base year (1994/95). The risk to present a moderate disability is not growing through the years; it is growing from 1994/95 to $1998 / 99$, but it is decreasing in 2000/01. The upward trend observed between 1994/95 and 2001/01 using descriptive methods seems to be due to changes in the demographic distribution of the population, at least for the year 2000/01. Also noteworthy is the absence of a clear trend in the risk of being in a severely disability state. Here again, even if the OR are not significant, the risk of a severe disability grows from 1994/95 to 1998/99, but the risk decreases in 2000/01. 
Lefrançois et al.: Trends and characteristics affecting disability among older Canadians in private households

Table 7. Overall disability rate and distribution of disabled Canadians aged 65 and older living in private households by severity levels and socio-demographic characteristics, 2000/01 CCHS.

\begin{tabular}{|c|c|c|c|c|c|}
\hline Independent variables & $\begin{array}{c}\text { Mild } \\
\text { disability }\end{array}$ & $\begin{array}{l}\text { Moderate } \\
\text { disability }\end{array}$ & $\begin{array}{c}\text { Severe } \\
\text { disability }\end{array}$ & $\begin{array}{c}\text { Total } \\
\text { disability }\end{array}$ & $\begin{array}{c}\text { Overall } \\
\text { disability rate }\end{array}$ \\
\hline Total & 46.9 & 37.9 & 15.2 & 100 & 33.9 \\
\hline \multicolumn{6}{|l|}{ Age groups } \\
\hline $65-74$ & 59.1 & 31.5 & 9.4 & 100 & 26.3 \\
\hline $75-84$ & 40.8 & 42.2 & 17.0 & 100 & 40.5 \\
\hline $85+$ & 25.3 & 46.5 & 28.2 & 100 & 63.8 \\
\hline \multicolumn{6}{|l|}{ Sex } \\
\hline Men & 44.8 & 42.4 & 12.8 & 100 & 29.5 \\
\hline Women & 48.2 & 35.1 & 16.6 & 100 & 37.3 \\
\hline \multicolumn{6}{|l|}{ Schooling level } \\
\hline Less than high school dipl. & 46.0 & 37.4 & 16.6 & 100 & 38.2 \\
\hline High school diploma & 46.9 & 38.7 & 14.4 & 100 & 31.7 \\
\hline Post-sec. dipl. other than univ. & 47.8 & 39.9 & 12.3 & 100 & 31.8 \\
\hline University degree & 51.9 & 33.9 & 14.2 & 100 & 21.7 \\
\hline \multicolumn{6}{|l|}{ Marital status } \\
\hline Married/in union & 51.4 & 34.7 & 13.9 & 100 & 30.2 \\
\hline Single & 41.0 & 34.6 & 24.4 & 100 & 32.5 \\
\hline Widowed/separated/divorced & 41.8 & 42.5 & 15.8 & 100 & 40.5 \\
\hline \multicolumn{6}{|l|}{ Region } \\
\hline Atlantic & 45.6 & 39.6 & 14.7 & 100 & 33.7 \\
\hline Quebec & 50.1 & 33.9 & 16.1 & 100 & 28.3 \\
\hline Ontario & 47.0 & 36.9 & 16.1 & 100 & 36.4 \\
\hline Prairies & 43.3 & 42.0 & 14.6 & 100 & 35.3 \\
\hline British Columbia & 46.7 & 41.3 & 11.9 & 100 & 35.1 \\
\hline \multicolumn{6}{|l|}{ Country of birth } \\
\hline Canada & 44.8 & 40.1 & 15.0 & 100 & 32.3 \\
\hline Outside Canada & 51.7 & 32.8 & 15.4 & 100 & 38.1 \\
\hline $\mathrm{V}=1,197,000$ & & & & & \\
\hline
\end{tabular}

Note: The distribution of disability levels is calculated among the disabled population.

\section{Socio-demographic characteristics associated with disability}

Table 7 presents the distribution (weighted sample) of respondents from the CCHS 2000/01 by socio-demographic characteristics and the three levels of disability. When comparing this distribution with the distribution of the whole period population (Tables 4), it is apparent that the two are quite similar except for the unusually high rate of severe disability among never-married persons (24.4 per cent in 2000/01 compared to 14.1 per cent for the entire period). The overall disability rate is almost identical (33.9 per cent in 2000/01 compared to 34.4 per cent for the entire period), but the disabilities tend to be a little more severe in 2000/01. Socio-demographic characteristics of the overall disabled population are similarly associated with the different disability levels.

Table 8 presents the regression parameters associated with variables in the model described in the methodology section, to determine the net effects of socio-demographic factors on the risk to be disabled.

Except for constant terms, only the effect of age is significant, and only for moderate and severe disability. However, for the three levels of disability, the important effect of age is observed, since the risks of being disabled are much higher among older people. In light of U.S. studies (Freedman 


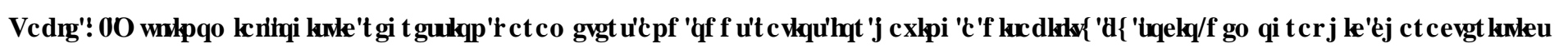

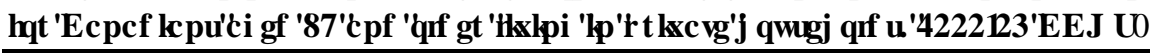

\begin{tabular}{|c|c|c|c|c|c|c|c|c|c|c|}
\hline & \multirow{2}{*}{$\begin{array}{c}\text { No } \\
\text { disability }^{(1)} \\
\end{array}$} & \multicolumn{3}{|c|}{ Mild disability } & \multicolumn{3}{|c|}{ Moderate disability } & \multicolumn{3}{|c|}{ Severe disability } \\
\hline & & Beta & Odds Ratio & P-Value & Beta & Odds Ratio & P-Value & Beta $C$ & Odds Ratio & P-Value \\
\hline \multicolumn{11}{|l|}{ Age groups } \\
\hline $65-74^{(2)}$ & - & - & - & - & - & - & - & - & - & - \\
\hline $75-84$ & - & 0.216 & 1.241 & 0.518 & 0.834 & 2.302 & $0.011^{* *}$ & 1.171 & 3.225 & $0.048^{* *}$ \\
\hline $85+$ & - & 0.666 & 1.947 & 0.249 & 1.793 & 6.009 & $0.000^{* *}$ & 2.502 & 12.211 & $0.001^{* *}$ \\
\hline \multicolumn{11}{|l|}{ Sex } \\
\hline $\operatorname{Men}^{(2)}$ & - & - & - & - & - & - & - & - & - & - \\
\hline Women & - & 0.411 & 1.509 & 0.195 & -0.035 & 0.966 & 0.915 & 0.751 & 2.119 & 0.226 \\
\hline \multicolumn{11}{|l|}{ Schooling level } \\
\hline Less than high school dipl. ${ }^{(2)}$ & - & - & - & - & - & - & - & - & - & - \\
\hline High school dipl. & - & -0.336 & 0.715 & 0.481 & -0.190 & 0.827 & 0.685 & -0.357 & 0.700 & 0.649 \\
\hline Post-sec. dipl. other than U. & - & -0.241 & 0.786 & 0.499 & -0.136 & 0.873 & 0.715 & -0.339 & 0.712 & 0.609 \\
\hline University degree & - & -0.640 & 0.527 & 0.282 & -0.781 & 0.458 & 0.191 & -0.732 & 0.481 & 0.459 \\
\hline \multicolumn{11}{|l|}{ Marital status } \\
\hline Married / in union ${ }^{(2)}$ & - & - & - & - & - & - & - & - & - & - \\
\hline Single & - & -0.061 & 0.940 & 0.921 & 0.127 & 1.136 & 0.842 & 0.663 & 1.941 & 0.498 \\
\hline Widowed/separated/divorced & - & 0.022 & 1.023 & 0.944 & 0.383 & 1.467 & 0.243 & 0.038 & 1.039 & 0.592 \\
\hline \multicolumn{11}{|l|}{ Region } \\
\hline Atlantic $^{(2)}$ & - & - & - & - & - & - & - & - & - & - \\
\hline Quebec & - & -0.173 & 0.841 & 0.738 & -0.356 & 0.701 & 0.475 & -0.043 & 0.958 & 0.962 \\
\hline Ontario & - & 0.133 & 1.143 & 0.759 & 0.231 & 1.259 & 0.593 & 0.388 & 1.475 & 0.632 \\
\hline Prairies & - & 0.009 & 1.009 & 0.984 & 0.201 & 1.222 & 0.660 & 0.163 & 1.177 & 0.838 \\
\hline British Columbia & - & 0.065 & 1.067 & 0.895 & 0.270 & 1.311 & 0.577 & -0.099 & 0.906 & 0.917 \\
\hline \multicolumn{11}{|l|}{ Country of birth } \\
\hline Canada $^{(2)}$ & - & - & - & - & - & - & - & - & - & - \\
\hline Outside Canada & - & 0.376 & 1.457 & 0.272 & -0.017 & 0.984 & 0.966 & 0.081 & 1.084 & 0.894 \\
\hline Constant & - & -1.458 & 0.233 & $0.043^{* *}$ & -1.897 & 0.150 & $0.011^{* *}$ & -2.231 & 0.107 & $0.025^{* *}$ \\
\hline $\mathrm{n}=23,294$ & & & & & & & & & & \\
\hline
\end{tabular}

(1) Dependent variable reference category

(2) Independent variable reference categories

$* * * \mathrm{p} \leq 0.01 ; * * 0.01<\mathrm{p} \leq 0.05 ; * 0.05<\mathrm{p} \leq 0.10 ; \dagger$ This model contains two additional control variables, which parameters

are not shown in this table. They are "interview mode" and "proxy interviews". 
Lefrançois et al.: Trends and characteristics affecting disability among older Canadians in private households

and Martin 1999; Freedman et al. 2008; Schoeni et al. 2008), a significant association between level of education and disability might be expected, which is not the case. The results presented here go in the expected direction; however, because the risk of being disabled for the three levels of severity is highest among those who did not graduate, and lowest among those with a university degree. In the latter, the risk to be moderately or severely disabled is about 52 per cent lower than among those without a diploma. For mild disability, the risk is about 47 per cent lower for those with a university degree. The risks associated with individuals with a high school degree and those with a post-secondary non-university degree are very close to each other for severe disability ( $\mathrm{OR}=0.700$ and 0.712 , respectively), but they are higher for older persons with post-secondary schooling for the three levels of severity.

The same situation is observed in terms of gender. The results indicate that women are more likely than men to be mildly or severely disabled (OR $=1.508$ and 2.119 , respectively). However it is the opposite for moderate disability, where men have a higher risk. This result is somewhat surprising, but it is consistent with the results presented in Table 7.

\section{Conclusion}

Between 1994/95 and 2000/01, the overall disability rate among older Canadians was 34.4 per cent, but when disaggregated by the four points in time (1994/95, 1996/97, 1998/99 and 2000/01), a downward trend was observed, as the rates decreased from 37.7 per cent in 1994/95 to 33.9 per cent in 2000/01. However, even if the proportion of disabled older persons decreased, the condition of those disabled people seems to be more severe as the prevalence of moderate disabilities increased over the period. On the one hand, mild disabilities decreased by 11 per cent, but on the other hand, moderate and severe disabilities increased by 14 per cent. We also observe that the decrease in overall disability can be mainly attributed to people in the younger age group, who are less likely to have a severe disability. However, it should be noted that the uncertainty around the estimated prevalence rates is high. When controlling for some socio-demographic variables to account for changes that might have occurred in the Canadian population structure since 1994/95, we found no significant change in the probability of being disabled across this period, whatever the level of severity.

In light of our results, no clear sign of deterioration in health status among older Canadians was found. Indeed, the decrease in the evolution of overall disability rates mitigates the impact of aging on the number of disabled people. Between 1994/95 and 2000/01, the rate of increase of the population 65 and older was 12 per cent, while that of the 65 and older disabled population was only 1.0 per cent. Yet as we look to the future, we know that it is not only the proportion of older people but the number of people who will need assistance that will need to be considered in planning to meet the needs of an aging population. If we focus on moderate and severe disability, the actual number of older people with a disability with such severity increased by 86,700 between 1994/95 and 2000/01 in Canada. Older persons with moderate and severe disability are more likely to require assistance from family/friend caregivers, or alternatively the paid home care system, in order to remain in their private households. If the decline in mild disabilities observed in the past decade in Canada (or the decline in the younger old-age group) holds true in the future, it will have a positive impact on the home-care services system and on the number of natural caregivers needed. The Boomers generation had fewer children than their parents thereby, reducing the number of potential informal caregivers at an older age.

The increased emphasis on receiving care in private homes and out of institutions may be driving some of the increases we observed on higher rates of moderate and severe disability among those disabled. With continued prominence being given to home care, it is anticipated that both the in- 
formal and formal systems of care will need to be prepared for higher and more complex care needs in the community (Canadian Healthcare Association 2009). Institutionalization is not the optimal solution; it is costly for government and not what is most desired by older people who want to remain in their home as long as possible. Consequently, the home-care services system must be expanded and optimized to meet the rising need.

The decrease in mild disabilities can be attributed to an increase in the health-related quality of life of the younger old. Disabilities tend to appear later, but seem then to be more severe. On the one hand, if such a trend continues, the fear of a "tsunami" of the Boomers cohort turning 65 and bankrupting the healthcare system is overstated. On the other hand, lower rates of disability may be an outcome of the interventions of a robust healthcare system. Successful treatments for acute illnesses and pharmacological interventions may enable more people to live disability-free for longer periods of time in older age. These findings are an initial step to a more complex understanding of the relationship among age, disability, and usage of formal and informal systems of support, as well as the impact of chronic diseases on functionality.

It must be noted again that the data used here have some important limitations, and the results should be interpreted with caution. First, the important variation of the disability rates between 1994/95 and 1996/97 is worrying, and may be explained by the significant change in the mode of interview. Second, as this analysis observed only four points in time, one survey could change the trends. American studies show that the estimated disability rates have been decreasing globally since the 1980s, but this decrease is not constant over the years. Further research would benefit from looking at a longer time-series, but no comparable data are available before 1994/95, and the 2003 and 2005 CCHS include important validity problems. Finally, the important differences of the sample sizes are problematic, especially for our reference year (1994/95). More balanced samples would have decreased the uncertainty (variance) of the estimates.

Readers should also note that this study used HUI variables to define disability. Those variables are well established in health research in Canada and have been used in several studies on disability. In other countries, like the United States, variables on activities of daily living and instrumental activities of daily living are chosen to define disability. While the HUI classification system is more associated to functional limitations, the activities of daily living are associated to the need of help. Some investigation of the same four surveys should be done with a different disability definition. Using variables on activities of daily living instead of the HUI variables might also shed a new light on the old-age disability trends in Canada.

As in many other developed countries, there is no appropriate data in Canada to answer questions about disability trends. In most cases, trends in disability are observed with time series of crosssectional surveys, whereas a longitudinal health survey would be better suited. To have strong and significant results on disability trends, there must be continuity in the survey methodology (sampling and mode of interview), and in the wording of the questions. This is especially a problem in Canada, because there is no data collection system like Medicare in the United States. However, the upcoming Canadian Longitudinal Study on Aging constitutes a promising tool to improve research on the health status of older Canadians.

\section{Acknowledgments}

The authors wish to thank Human Resources and Skills Development for financial support for this research. The views expressed in this paper are those of the authors, and do not necessarily reflect the views of Human Resources and Skills Development or of the Federal Government. 
Lefrançois et al.: Trends and characteristics affecting disability among older Canadians in private households

\section{References}

Canadian Healthcare Association. 2009. Home care in Canada: From the margins to the mainstream. Ottawa: Canadian Home Care Association. http://www.cha.ca/documents/Home_Care_in_ Canada_From_the_Margins_to_the_Mainstream_web.pdf (retrieved December 20, 2011).

Carrière, G. 2006. Senior's use of home care. Health Reports 17(4):47-51 (Cat. No. 82-003). Ottawa: Statistics Canada.

Carrière, Y., J. Keefe, J. Légaré, X. Lin, and G Rowe. 2007. Population aging and immediate family composition: Implications for future home care services. Genus LXIII(1-2):11-31.

Chen, J., and W.J. Millar. 2000. Are recent cohorts healthier than their predecessors? Health Reports 11(4):9-23 (Cat. No. 82-003). Ottawa: Statistics Canada.

CIHI (Canadian Institute for Health Information). 2009. National health expenditure trends 1975 to 2009. Ottawa: Canadian Institute for Health Information. http:/ / secure.cihi.ca/cihiweb/products/ National_health_expenditure_trends_1975_to_2009_en.pdf (retrieved December 7, 2011).

Côté, L., R. Courtemanche, and B. Caron. 2005. Comparabilité entre les cycles 1.1 et 2.1 de l'Enquête sur la santé dans les collectivités canadiennes : impact du changement apporté à la répartition de l'échantillon selon la base de sondage. Québec : Institut de la statistique du Québec.

Feeny, D., W. Furlong, G.W. Torrance, C.H. Goldsmith, Z. Zhu, S. DePauw, S. Denton, and M. Boyle. 2002. Multiattribute and single-attribute utility functions for the health utilities index Mark 3 system. Medical Care 40(2):113-128.

Freedman, V.A., and L.G. Martin. 1999. The role of education in explaining and forecasting trends in functional limitations among older Americans. Demography 36(4):461-473.

Freedman, V.A., E. Crimmins, R.F. Schoeni, B.C. Spillman, H. Aykan, E. Kramarow, K. Land, J. Lubitz, and T. Waidmann. 2004. Resolving inconsistencies in trends in old-age disability: Report from a technical working group. Demography 41(3):417-441.

Freedman, V.A., L.G. Martin, R.F. Schoeni, and J.C. Cornman. 2008. Decline in late-life disability: The role of early- and mid-life factors. Social Sciences and Medicine 66(7):1588-1602.

Jagger, C., C. Gillies, E. Cambois, H. Van Oyen, W. Nusselder, J.M. Robine, and EHLEIS Team. 2009. Trends in disability-free life expectancy at age 65 in the European Union 1995-2001: A comparison of 13 EU countries. European Health Expectancy Monitoring Unit (Technical report 2009_5.1). France: EHEMU.

Lafortune, G., G. Balestat, and Disability Study Expert Group Members. 2007. Trends in severe disability among elderly people: Assessing the evidence in 12 OECD countries and the future implications. Organization for Economic Cooperation and Development (Health working papers, 26).

Lefrançois, G. 2011. Tendances de l'incapacité chez les aînés au Canada, et caractéristiques sociodémographiques associées, 1994-2005. MA thesis. Montréal: Université de Montréal, 90 p. http://hdl.handle.net/1866/4846 (retrieved December 7, 2011).

Link, M.W., and M. Fahimi. 2008. Telephone survey sampling, in Sampling of populations: Methods and applications, 4th edn, edited by P. S. Levy and S. Lemeshow. Hoboken, NJ: Wiley, p. 455-487. 
McColl, M.A., S. Shortt, M. Gignac, and M. Lam. 2011. Disentangling the effects of disability and age on health service utilisation. Disability and Rebabilitation 33(13-14):1253-1261.

Rotermann, M. 2006. Seniors' healthcare use. Supplement to Health Reports 16:35-49 (Cat. No. 82-003). Ottawa: Statistics Canada.

Schoeni, R.F., V.A. Freedman, and R.B. Wallace. 2001. Persistent, consistent, widespread, and robust? Another look at recent trends in old-age disability. The Journals of Gerontology, Series B 56B(4):S206S218.

Schoeni, R.F., V.A. Freedman, and L.G. Martin. 2008. Why is late-life disability declining? The Milbank Quarterly 86(1):47-89.

St-Pierre, M., and Y. Béland. 2004. Mode effects in the Canadian Community Health Survey: A comparison of CAPI and CATI. Proceedings of the American Statistical Association meeting, Toronto, August 8-12.

Statistics Canada. 2007. Participation and Activity Limitation Survey 2006: Analytical report. (Cat. No. 89-628-XIE). Ottawa: Statistics Canada.

Statistics Canada. 2010. Table 051-0001 - Estimates of population, by age group and sex for July 1, Canada, provinces and territories, annual (CANSIM database). Ottawa: Statistics Canada.

Torrance, G.W., D.H. Feeny, W.J. Furlong, R.D. Barr, Y. Zhang, and Q. Wang. 1996. Multiattribute utility function for a comprehensive Health Status Classification System. Health Utilities Index Mark 2. Medical Care 34:702-722.

Waidmann, T.A., and K. Liu. 2000. Disability trends among elderly persons and implications for the future. The Journals of Gerontology, Series B 55B(5): S298-S307.

Wilkins, R., J. Chen, and E. Ng. 1994. Changes in health expectancy in Canada from 1986 to 1991, in Advances in Health Expectancies: Proceedings of the $7^{\text {th }}$ Meeting of the International Network on Health Expectancy (REVES), edited by C. Mathers, J. McCallum, and J.M. Robine. Canberra: Australian Institute of Health and Welfare, p. 115-132.

Wolf, D.A., K. Hunt, and J. Knickman. 2005. Perspectives on the recent decline in disability at older age. The Milbank, Quarterly 83(3):365-395.

Wolfson, M.C., and K. Moore. 2010. On the replacement adequacy of Canada's retirement income system estimates using Statistics Canada's LifePaths Microsimulation Model. Paper presented at the 31st General Conference of The International Association for Research in Income and Wealth, St. Gallen (Switzerland), August 22-28.

Wolfson, M.C., and G. Rowe. 2005. Disability and informal support, prospects for Canada. Paper presented at the Workshop "Understanding Trends in Disability among Elderly Populations and the Implications of Demographic and Non- Demographic Factors for Future Health and Longterm Care Costs," organized by the European Commission, the Working Group on Ageing, and the Organization for Economic Cooperation and Development, Brussels, February 21-22. 